\title{
Environmental forcings and micro-seismic monitoring in a rock wall prone to fall during the 2018 Buran winter storm
}

\author{
D. D'Angiò ${ }^{1}$ (D ) A. Fantini ${ }^{2} \cdot$ M. Fiorucci ${ }^{1} \cdot$ R. Iannucci $^{1} \cdot$ L. Lenti ${ }^{3,4} \cdot$ G. M. Marmoni ${ }^{1}$. \\ S. Martino ${ }^{1}$
}

Received: 18 June 2020 / Accepted: 19 January 2021 / Published online: 13 February 2021

(C) The Author(s) 2021

\begin{abstract}
This study reports a comparative analysis of the environmental conditions and micro-seismicity recorded on a rock wall resulting from an intense meteorological event. The findings are focused on a quarry wall located in the Acuto Field Laboratory (Central Italy), where multi-parametric environmental monitoring is operating and an Artificial intelligence Camera Prototype has been placed to detect rock falls reaching a railway target. Six accelerometers were installed to detect micro-seismic events caused by the expected strong thermal transient caused by the Buran storm on February 2018. Within a few hours, a steep decrease in the average air and rock mass temperature down to $8{ }^{\circ} \mathrm{C}$ was recorded, and $-4{ }^{\circ} \mathrm{C}$ and $-8{ }^{\circ} \mathrm{C}$ were reached for the rock and air temperatures, respectively. A total of 103 micro-seismic events were analysed with respect to both rainfall and thermal forcing: while no correlation with rainfall was reported, the steep thermal transient was responsible for the strain effect that occurred during the heating phase of the rock mass following the Buran storm. An elastic deformation event with a maximum daily amplitude of 165 $\mu$ strain was recorded by the strain gages installed on the mm-joints due to the rock heating and cooling caused by the variation in temperature. The collected evidences show the relevance of short thermal transients in modifying stress conditions within rock masses and their relationship to a peculiar micro-seismic response. The main outcomes established the key role played by integrated monitoring systems to better understand the relationship between vibrational behaviour and environmental forcings in terms of understanding the precursors to rock failure.
\end{abstract}

Keywords Rock fall $\cdot$ Micro-seismic monitoring $\cdot$ Forcings analysis $\cdot$ Slope stability

D. D’Angiò

danilo.dangio@uniroma1.it

1 Earth Sciences Department, Acuto Field Laboratory and CERI - Research Centre for Geological Risk, University of Rome "Sapienza", P.le Aldo Moro n.5, 00185 Rome, Italy

2 Tecnostudi Ambiente S.r.1, P.zza Manfredo Fanti n.30, 00185 Rome, Italy

3 GERS-SRO, Univ Gustave Eiffel, IFSTTAR, 4-20 Boulevard Newton Cité Descartes, 77447 Marne-la-Vallée Cedex 2, Champs sur Marne, France

4 Cerema Méditerranée, Equipe-Projet MOUVGS, 500 route des Lucioles, 06903 Sophia-Antipolis, France 


\section{Introduction}

Rock slope stability is currently investigated through several approaches and techniques as rock falls contribute to landslide hazards due to their fast movement and the numerous factors that can trigger their occurrence (Varnes 1978; Menéndez Duarte and Marquìnez 2002; Fischer et al. 2012; D’Amato et al. 2016). A contribution to risk mitigation strategies can be provided by monitoring and studying several preparatory factors (to both transient and continuous forcing) that when combined, can influence rock fall occurrence (Gunzburger et al. 2005). More specifically, thermal stresses (Gischig et al. 2011; Wang et al. 2016; Grämiger et al. 2018), rainfall (Krautblatter and Moser 2009; Delonca et al. 2014), and seismic inputs (Moore et al. 2012; Koukouvelas et al. 2015) combined with long-term deformation (Brückl and Parotidis 2005; Grøneng et al. 2010; Xu et al. 2014b) are among the main causes of rock mass damage. These phenomena can progressively lead to the development of weak sectors within the rock mass that have the potential to evolve into failures. In fact, small-size failures usually originate from highly jointed rock masses that have been stressed by recurrent forcing, such as rainfalls and daily thermal cycles that can induce freezing and thawing events (Matsuoka and Sakai 1999; Gunzburger et al. 2005; Mateos et al. 2012; Collins and Stock 2016; Dietze et al. 2017; Matsuoka 2019). All of these factors are responsible for the accumulation of inelastic deformations within the rock mass, leading to permanent damage, i.e., the non-negligible reduction of mechanical strength. Although the role of small-size failures in controlling rock slope stability seems to be self-evident, how these processes interact and progress over time is still far from completely understood.

Several monitoring strategies are usually adopted for managing the risk associated with rock falls by employing sensors specifically aimed at analysing the effects (i.e., elastic or inelastic) induced by natural and anthropic forcing that can negatively affect slope stability. While more traditional stress-strain sensors allow the direct investigation of specific portions of a rock mass by monitoring peculiar conditions across major joints (Loew et al. 2017), micro-seismic monitoring devices represent an opportunity for detecting incipient variations within a rock mass volume, providing information about the modification of its physical and/or mechanical properties (Papini et al. 2009; Xu et al. 2012; Colombero et al. 2016; Provost et al. 2018; Meyer et al. 2019) and quantitative indications of the vibrational and dynamic behaviour of prone to failure rock blocks. In particular, dynamic behaviour is assessed in terms of evaluating the seismic ambient noise (Bottelin et al. 2013; Kleinbrod et al. 2017; Valentin et al. 2017), increases in the recorded micro-seismicity (Senfaute et al. 2009; Levy et al. 2011) and the shifting of the main resonance frequency before a generalised collapse (Got et al. 2010; Lévy et al. 2010). Regarding environmental parameters, Helmstetter and Garambois (2010) studied seismic signals collected on the Séchilienne rockslide and observed a correlation between micro-seismic emissions and rainfall with the occurrence of rock falls. Similar outcomes were noted by Arosio et al. (2018), who analysed a three-year-long micro-seismic record collected on a limestone cliff. Regarding thermal forcing, the relevance of daily temperature variations and freeze-thaw cycles in the predisposition of rock falls has been widely documented (Mateos et al. 2012; Walbert et al. 2015; D’Amato et al. 2016). Additionally, the analysis of micro-seismic and acoustic emission datasets can help in monitoring ongoing damaging processes at a smaller scale (from metric to centimetric) (Xu et al. 2014a; Zhou et al. 2018; Colombero et al. 2018) since the inelastic strain associated with thermal oscillations is released as micro-seismic and acoustic emissions (Occhiena et al. 2012; Collins et al. 2014; Weber et al. 2018). Based 
on the available literature, only a few studies have identified an increase in micro-seismic events during the rapid and intense lowering of air temperature, especially during the cooling phase, e.g. Amitrano et al. (2010) and Occhiena et al. (2012) at the Matterhorn site.

To study the complex interactions between meteorological forcings acting within rock masses and induced deformations, a permanent multi-sensor strain and environmental monitoring system was installed in a Field Laboratory located in an abandoned quarry and managed by the Department of Earth Sciences and the Research Centre for Geological Risks (CERI) of the University of Rome "Sapienza". This monitoring system focuses on a $20 \mathrm{~m}^{3}$ protruding rock block that is kinematically predisposed to evolve towards failure and is sensitive to cyclical thermomechanical stress (Fiorucci et al. 2018). During an intense meteorological perturbation forecasted for the end of February 2018, during which a drastic drop of temperature associated with intense rain and snowfall was expected, an accelerometer array was installed to temporarily integrate with the permanent environmental monitoring system. In this study, the outputs from the monitoring system throughout the intense meteorological event are reported and discussed: micro-seismic data are compared with environmental (i.e., rainfalls, air, and rock mass temperatures) and deformational (i.e., extensometers and strain gauges) data to investigate the effects induced in the vibrational response of the rock mass to severe weather conditions.

\section{The Acuto Field Laboratory}

\subsection{The multi-parametric monitoring system}

To study the long-term rheological behaviour of rock masses exposed to environmental forcings (such as rainfalls, wind, daily and seasonal thermal cycles) and evaluate their role in inducing instability, a multi-sensor monitoring system has been installed since autumn 2015 in the abandoned quarry that was selected as a Field Laboratory (Fantini et al. 2017b). The quarry is located in the Acuto municipality $100 \mathrm{~km} \mathrm{SE}$ of Rome and is characterised by a $500 \mathrm{~m}$ long and sub-vertical quarry front made up of Cretaceous limestone that reaches a height up to $50 \mathrm{~m}$ and was intensively pitted until the late $70 \mathrm{~s}$. The monitored area is located in the NW sector of the quarry, where a $20 \mathrm{~m}^{3}$ rock block jutting out from the quarry wall is separated from the quarry wall itself by a decimetric-wide sub-vertical joint. The rock block has been instrumented with: (1) one thermometer for measuring the rock mass temperature installed at a depth of $8 \mathrm{~cm}$ from the free surface exposed eastward (sensitivity: $0.1^{\circ} \mathrm{C}$ ); (2) six strain gages (sensitivity: $1 \mu$ strain) installed over the rock block on micro-joints; and (3) four extensometers (sensitivity: $0.01 \mathrm{~mm}$ ) installed on the steeply dipping open joints that separate the rock block from the wall behind it (Fiorucci et al. 2020). Additionally, the monitoring system is completed by a fully equipped weather station placed at the top of the quarry wall that is composed of an air thermometer (measurement range $-40{ }^{\circ} \mathrm{C} /+60{ }^{\circ} \mathrm{C}$ ), a hygrometer, a rain gage (sensitivity: $0.2 \mathrm{~mm} \mathrm{H}_{2} \mathrm{O}, \mathrm{WMO}$ standard) and an anemometer for determination of wind speed and wind direction (Fantini et al. 2017b). Meteorological, thermal, and strain data are sampled each minute and collected by a digital data logger set up to acquire data every minute. An Artificial intelligence Camera Prototype (AiCP) has also been installed in front of the quarry wall to detect rock falls impacting a potential target (i.e., a railway track) placed on the ground just below the monitored rock block (Fantini et al. 2017a). AiCP frame acquisition and processing are based on a change detection algorithm that continuously operates over a specified Region 
of Interest (RoI) focused on the railway track. Alerts are automatically sent if new volumes are detected within the RoI (Fantini et al. 2015, 2017a; Leone et al. 2016).

In addition to this permanent monitoring system, an array of seismic sensors was temporarily installed before the expected drop in temperature related to the incoming intense meteorological event. On 23 February 2018, 6 Bruel \& Kjaer one-component accelerometers (type 8344: frequency range $0.2-3000 \mathrm{~Hz}$, sensitivity $250 \mathrm{mV} / \mathrm{ms}^{-2}$ ) were deployed on the sides of the protruding monitored rock block, spaced 15-20 cm apart along a horizontal alignment across major- and micro-joints over a space corresponding to the daily thermal active layer (Fiorucci et al. 2018; Marmoni et al. 2020). These sensors were tightened to studs previously fixed within the rock mass to ensure the best coupling with the rock mass matrix. Accelerometers 1, 2, and 3 were placed on the rock block; accelerometer 4 was fixed on a rock block portion delimited on both sides by two main joints; and accelerometers 5 and 6 were installed on the rock wall to monitor and weight the vibrational behaviour of both the rock wall and rock block (Fig. 1). In addition to the possibility of

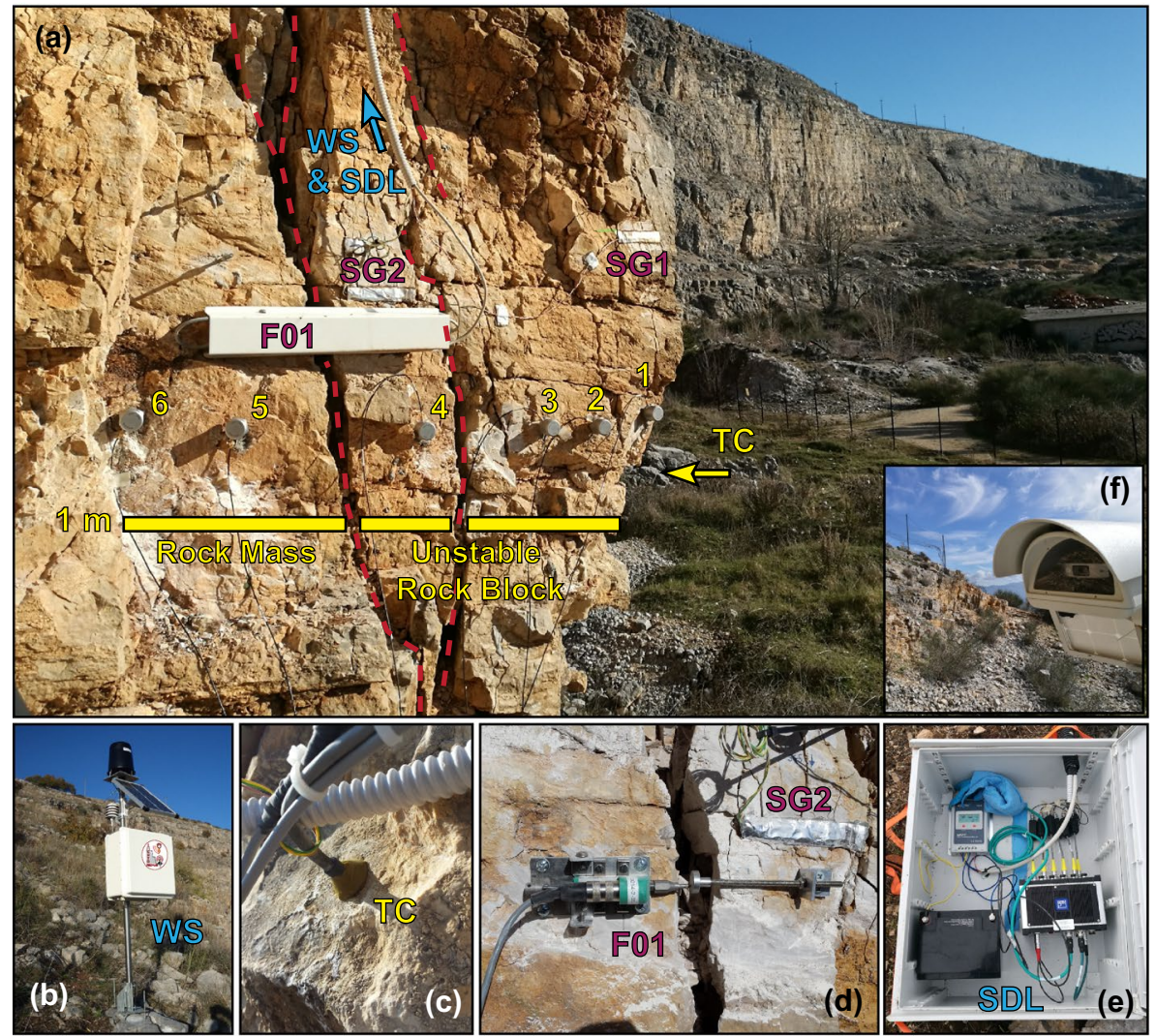

Fig. 1 View of the Acuto quarry wall where the Field Laboratory is hosted; in the foreground, the monitored rock block side is shown; the positioning and IDs of the accelerometers (from 1 to 6) and on-rock devices are marked a. The small frames provide details of some devices: fully equipped weather station (WS) b; thermocouple (TC) installed inside the rock c; joint gage (F01) on the main joint and strain gage (SG1 and SG2) on the -joint d; seismic data logger (SDL) e; Artificial intelligence Camera Prototype (AiCP) $\mathbf{f}$ 
investigating the vibrational behaviour and the effect of thermal cyclical forcings across major- and micro-joints, this set up also allowed the comparison of vibrational data with strain data collected by the closest extensometer and strain gages. In this arrangement, all the accelerometers were NS oriented or normally oriented with respect to the orientation of the rock block side. The accelerometers were connected via cables to an HBM digital acquisition system composed of a signal amplifier (SomatXR MX1601B-R) and a data processor (SomatXR CX23-R), which was set up to perform continuous mode acquisition with a sampling frequency of $2400 \mathrm{~Hz}$. The power was first supplied by three $40 \mathrm{Ah}$ lead batteries replaced every 3 days, and then, beginning 9 March 2018, by a $105 \mathrm{~W}$ solar panel equipped with a backup battery.

\subsection{The Buran winter storm}

Based on the environmental data collected since Autumn 2015 and the decennial weather dataset collected by Blasi (1994), the Acuto site belongs to a temperate sub-mountain climatic region characterised by dry summers and wet winters, with rainfall mainly distributed between late autumn and spring. Winters at the site are mild, with an average annual variable temperature of $12.0-13.6^{\circ} \mathrm{C}$, and the minimum average temperature of the coldest month is rarely lower than $0{ }^{\circ} \mathrm{C}$. Annual rainfall exceeds $1400 \mathrm{~mm}(1430-1606 \mathrm{~mm})$, with a few summer rains up to $173-200 \mathrm{~mm}$ each.

Although the weather conditions are not extreme, sudden temperature decreases, as well as snowfalls associated with meteorological perturbations, can occasionally strike this area with a recurrence of several years. During winter 2017-2018, Central and Eastern Europe were affected by an intense meteorological event characterised by the incoming cold air associated with the Buran, a strong and cold wind blowing from the northeast that originates in the steppes of the Sarmatic Plain. Between the end of February and March 2018, the air temperature reached a minimum of $-40{ }^{\circ} \mathrm{C}$ in the Russian Plateau and tens of degrees below $0{ }^{\circ} \mathrm{C}$ in Italy, where significant snowfall covered northern and central Italy (Fig. 2).

At the Acuto Field Laboratory, a sharp temperature drop accompanied by snowfall occurred, with the latter contributing to keeping the air temperature below $0{ }^{\circ} \mathrm{C}$ for almost three subsequent days (Fig. 2). Marked temperature changes with amplitudes of up to $18^{\circ} \mathrm{C}$ were registered for the air mass in one and a half days, during which minimum temperatures of $-7.7{ }^{\circ} \mathrm{C}$ for the air and $-3.8^{\circ} \mathrm{C}$ for the rock mass were reached. This cooling scenario constituted a short thermal transient in the seasonal temperature trend, as indicated by variations higher than $8{ }^{\circ} \mathrm{C}$ recorded for the average air temperature during the Buran storm (26 February-1 March 2018) with respect to the period before and after it.

\section{Materials and methods}

Environmental and micro-seismic data were analysed throughout a time span of 18 days from 23 February to 13 March 2018 (i.e., the acquisition period of the micro-seismic monitoring system), during which a substantial difference between the air and rock mass temperature records was observed. Based on the air and rock mass average temperatures, two time windows were considered: (1) before and after the Buran storm (from 23/02/2018 00:00 to midnight of 26/02/2018 and from 02/03/2018 00:00 until the end of 13/03/2018, respectively), and (2) during the Buran storm period (from 26/02/2018 00:00 to 02/03/2018 

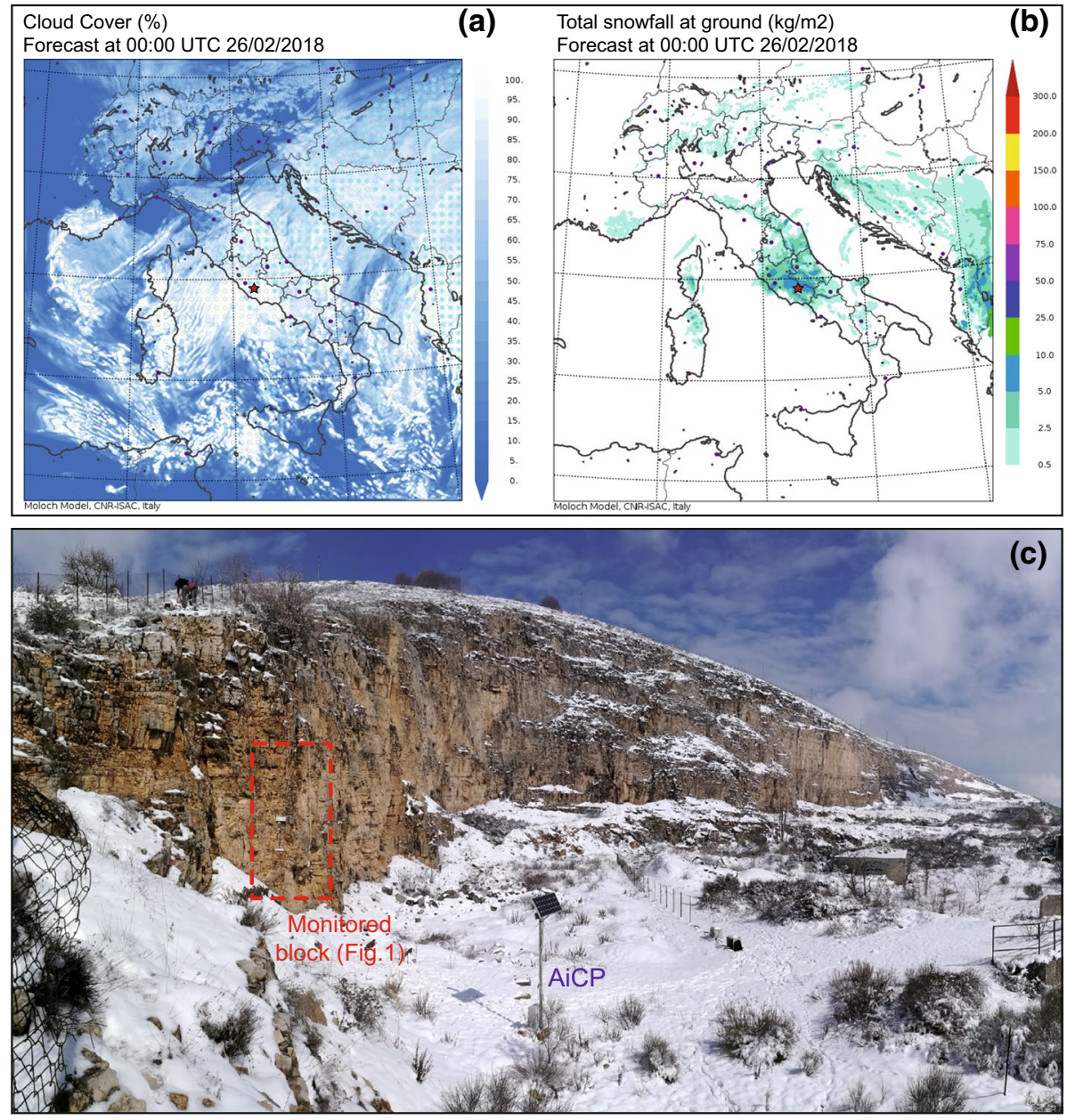

Fig. 2 Weather forecast of cloud cover (a) and snow accumulation over $3 \mathrm{~h}$, (b) released by CNR-ISAC for midnight of 26 February 2018. Resulting snow cover at the Acuto Field Laboratory after the Buran winter storm (c). Red stars indicate the location of the study area

Table 1 Mean, maximum, and minimum temperatures recorded at Acuto Field Laboratory during and preceding/following the Buran storm

\begin{tabular}{|c|c|c|c|c|c|c|}
\hline & \multicolumn{3}{|c|}{$\begin{array}{l}\text { Buran } \\
\text { 26/02 00:00 } \div 02 / 03 \text { 00:00 }\end{array}$} & \multicolumn{3}{|c|}{$\begin{array}{l}\text { Pre_post-Buran } \\
23 / 02 \text { 00:00 } \div 26 / 02 \\
00: 00 \\
02 / 0300: 00 \div 13 / 03 \\
00: 00\end{array}$} \\
\hline & Mean & Max & Min & Mean & Max & Min \\
\hline $\mathrm{T}$ rock $\left({ }^{\circ} \mathrm{C}\right)$ & 1.4 & 9.7 & -3.8 & 7.1 & 19.0 & 2.5 \\
\hline $\mathrm{T}$ air $\left({ }^{\circ} \mathrm{C}\right)$ & -1.2 & 9.1 & -7.7 & 6.8 & 15.4 & -0.3 \\
\hline
\end{tabular}


00:00), which were characterised by mean temperatures of the rock matrix of 1.4 and $7.1{ }^{\circ} \mathrm{C}$, respectively (Table 1 ). Approximately 10 days after the end of the Buran storm, during maintenance of the micro-seismic array, rock fall debris was directly surveyed in the area of the railway target. As the only rock fall that occurred in this quarry sector since the installation of the permanent monitoring system in 2015, the AiCP frames were also analysed to better constrain its temporal occurrence; moreover, additional analyses and surveys were planned with the aim of locating its source area and to estimate the detached volume (Figs. 3 and 4).

Two 3D models of the rock wall were compared: the first one obtained by a Leica MS60 Multistation before the Buran storm and the second one obtained following a photogrammetric survey performed in the days after the instability event. The pre-event $3 \mathrm{D}$ model was obtained using a sampling size of $5 \times 5 \mathrm{~cm}$, an angular precision of $1^{\prime \prime}$ and an accuracy of 1-2 mm for a distance of $50 \mathrm{~m}$, while 158 images with a resolution of $3968 \times 2976$ pixels were considered for the post-event 3D model. Both models were scaled to the same resolution, and a volumetric change detection analysis was carried out using the M3C2 algorithm (Lague et al. 2013) managed by the CloudCompare open-source software.

\subsection{Analysis of the micro-seismic dataset}

The micro-seismic records collected during the 18 days of monitoring were analysed using the SAC software (Seismic Analysis Code; Goldstein et al. 2003; Goldstein and Snoke 2005) and customised scripts implemented in MATLAB. A $5 \mathrm{~Hz}$ high-pass filter was applied to all the datasets to adjust for the inaccurate low-frequency response of the installed accelerometers. A routine based on the STA/LTA algorithm (Allen 1982) was applied to automatically detect micro-seismic (MS) events over ambient noise variations to perform an objective analysis of the seismic records and to avoid uncertainties and possible loss of information in the recognition of the MS events. The mean of the amplitude in a short-time window (STA) was compared to the mean of the amplitude calculated over a longer time span (LTA) considering the absolute value of the seismic records. If the STA/ LTA ratio exceeded a user-defined triggering threshold, the event was registered until the ratio decreased to a de-triggering threshold. In this case, STA was set to $0.01 \mathrm{~s}$, LTA to $1 \mathrm{~s}$

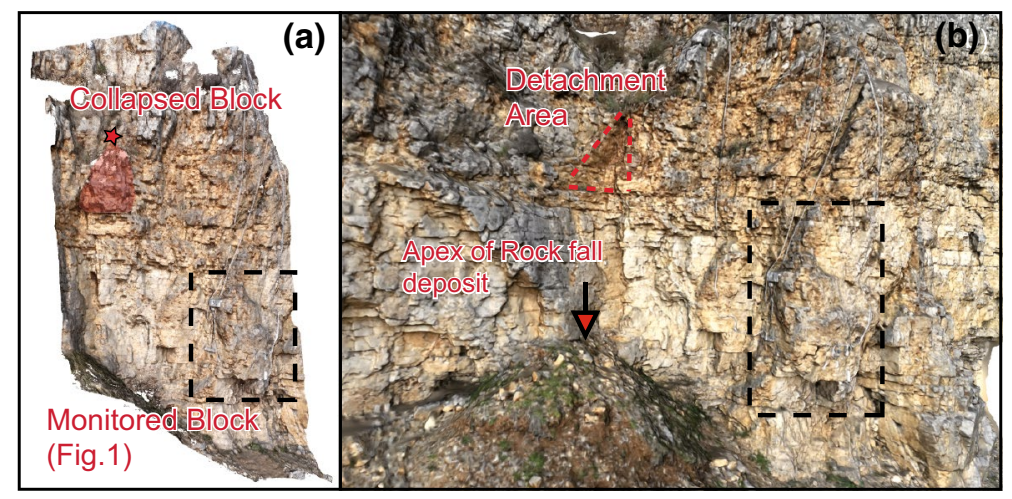

Fig. 3 Views of the rock fall source area, pre- (a) and post-event (b). The rock volume involved in the instability is highlighted in light red and was released by a wedge-shaped detachment area (dashed red triangle). The location of the monitored rock block is also shown (dashed black rectangles) 

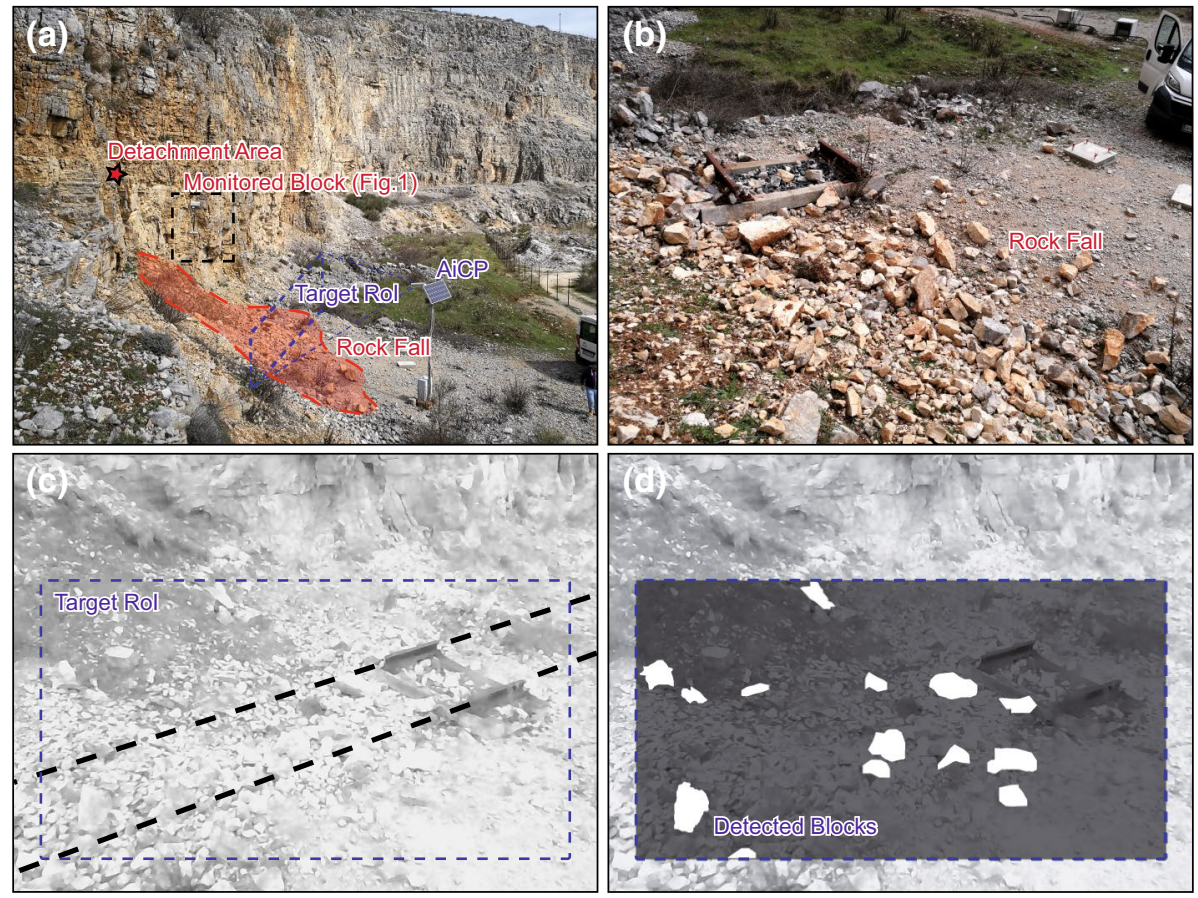

Fig. 4 a Picture of the main rock fall scenario with the detachment area (fallen rock volume of approximately $1 \mathrm{~m}^{3}$ ) and accumulation surface highlighted. The monitored rock block, the AiCP, and the target RoI are also shown; b debris that reached the railway target; $\mathbf{c}$ background scenario by the AiCP with the RoI bounded by a blue dashed frame; $\mathbf{d}$ scenario resulting from change detection analysis carried out by the AiCP: white pixels inside the RoI represent the detected fallen blocks

and STA/LTA to $4 \mathrm{~s}$ for both the triggering and de-triggering thresholds. The pre-and postevent times were set to $0.5 \mathrm{~s}$ to ensure the selection of the entire event. In the case of the repeated exceedance of the established STA/LTA ratio within a time span of $2 \mathrm{~s}$, multiple events were recorded as a single event. The input parameters for the STA/LTA routine were selected following several iterations to obtain the best trade-off suitable for identifying events. Following Trnkoczy (2012), the STA duration selected was shorter than the shortest event expected, and the LTA length progressively varied until the obtained detections included reliable waveforms, validated by visual screening.

Furthermore, to reduce false positives due to signals not related to the rock mass deformation (i.e., single spikes, raindrops hitting surfaces, etc.), only quasi-simultaneous events were considered by selecting those detected on more than one sensor within a time span of $0.1 \mathrm{~s}$. Signals recorded on at least two sensors returned background information about the intensity and time distribution of the events but were still affected by the presence of erroneously selected spurious signals. For this reason, the discussion only considered events detected by at least five sensors, further subsampled following a manual check of the waveforms and spectrograms to discard problematic MS signals, evaluating the coherence in the FFT and spectrograms for each signal using the maximum frequency from the spectrogram. 
Table 2 Distribution of the MS events collected in the dataset $\mathrm{B}$ according to dry and rainy periods, during and pre/post the Buran storm

\begin{tabular}{lllr}
\hline Periods & Buran (max/day) & Pre/post-Buran (max/day) & Total \\
\hline Rainy & $39(20$ on 28 Febru- & $20(7$ on 2 March) & 59 \\
& ary $)$ & & \\
Dry & $40(16$ on 1 March $)$ & $4(2$ on 2 March $)$ & 44 \\
Total & $79(36)$ & $24(9)$ & 103 \\
\hline
\end{tabular}

To weight the role of the recorded severe weather conditions in inducing micro-seismicity within the monitored rock mass, the micro-seismic dataset was compared to the rainfall intensity and the rock mass temperature datasets. Two subsets of MS data were considered according to the different temperature conditions that occurred in the defined pre/postBuran and Buran periods; each subset was further dichotomised into rainy and dry periods to obtain four subsets of the MS events (Table 2). In particular, the time intervals were classified as "rainy" when the cumulative rainfalls were not null for at least $2 \mathrm{~h}$. As a result, the MS events were counted by maintaining the environmental conditions, allowing a comparison of the occurrence of the MS events with the temperature trends in the absence of rainfall and the evaluation of the effect of rainfall during stationary temperature conditions.

To evaluate the possible correlation between micro-seismicity and rainfall, the validated MS events that occurred in the pre/post-Buran periods were clustered according to the classes of total cumulative rainfall in two hours $(<1 \mathrm{~mm} ; 1 \leq \mathrm{mm}<3 ; \geq 3 \mathrm{~mm})$. To exclude the possible interference due to rainfall, the MS events that occurred during dry periods (both during and pre/post the Buran storm) were selected and clustered with respect to the thermal gradient derived in two hours and to intervals of $2{ }^{\circ} \mathrm{C}$ in absolute temperature. The 2-h interval was considered to better observe temperature variations and was then used to accumulate rainfalls, with the aim of clustering MS events that occurred within the same time intervals. The classes considered for cumulative rainfalls were set arbitrarily.

Moreover, following Helmstetter and Garambois (2010) and Arosio et al. (2018), crosscorrelation between the MS dataset, rainfall, and rock temperature gradient was performed. Cross-correlation is a mathematical operator that allows the similarity between two time series to be compared when provided, providing their offset as a temporal lag dependent on the sample step of the inputted time series, which must be the same for both. Rainfall and MS data were cumulated hourly, and the rock temperature gradient was accordingly derived. Periods with missing values from the MS data (due to a lack of power supply) were discarded from all the datasets to not affect the final results. Then, cross-correlation was performed on three time series, which considered the entire monitoring period, the Buran storm phase, and the pre/post-Buran period.

\section{Results}

Differential analysis of the 3D models of the quarry wall enabled the examination of the detachment area of the rock fall that was released from the westernmost portion of the rock wall, approximately $10 \mathrm{~m}$ far from the monitored rock block (Figs. 3 and 4), which corresponded to a highly jointed portion of the rock mass. This comparison also enabled estimation of a rock fall volume of approximately $1 \mathrm{~m}^{3}$. 
Analysis of the frames collected by the AiCP facilitated the identification of $13 \mathrm{dm}$ rock blocks in the debris within the RoI (Fig. 4), while another rock block was visible at the apex of the rock fall deposit (Fig. 3). Moreover, by considering the frames with and without the rock fall deposit, it was possible to establish that the time window in which the rock fall occurred ranged between 11 and 12 March. Unfortunately, at that time, the micro-seismic monitoring was not operating due to a lack of power supply; therefore, the vibrational signal of the rock fall impact was not recorded.

However, excluding short-time gaps due to a lack of power supply, the accelerometer array was operational for most of the 18-day monitoring period, as highlighted by the distribution of the 18,802 events detected by at least two sensors scattered throughout the whole period, particularly during the Buran storm phase (Fig. 5a).

To reduce false positives, only the events picked by 5 accelerometers were considered (1646 detections). From this dataset, a manual selection of the waveforms was carried out

(a)
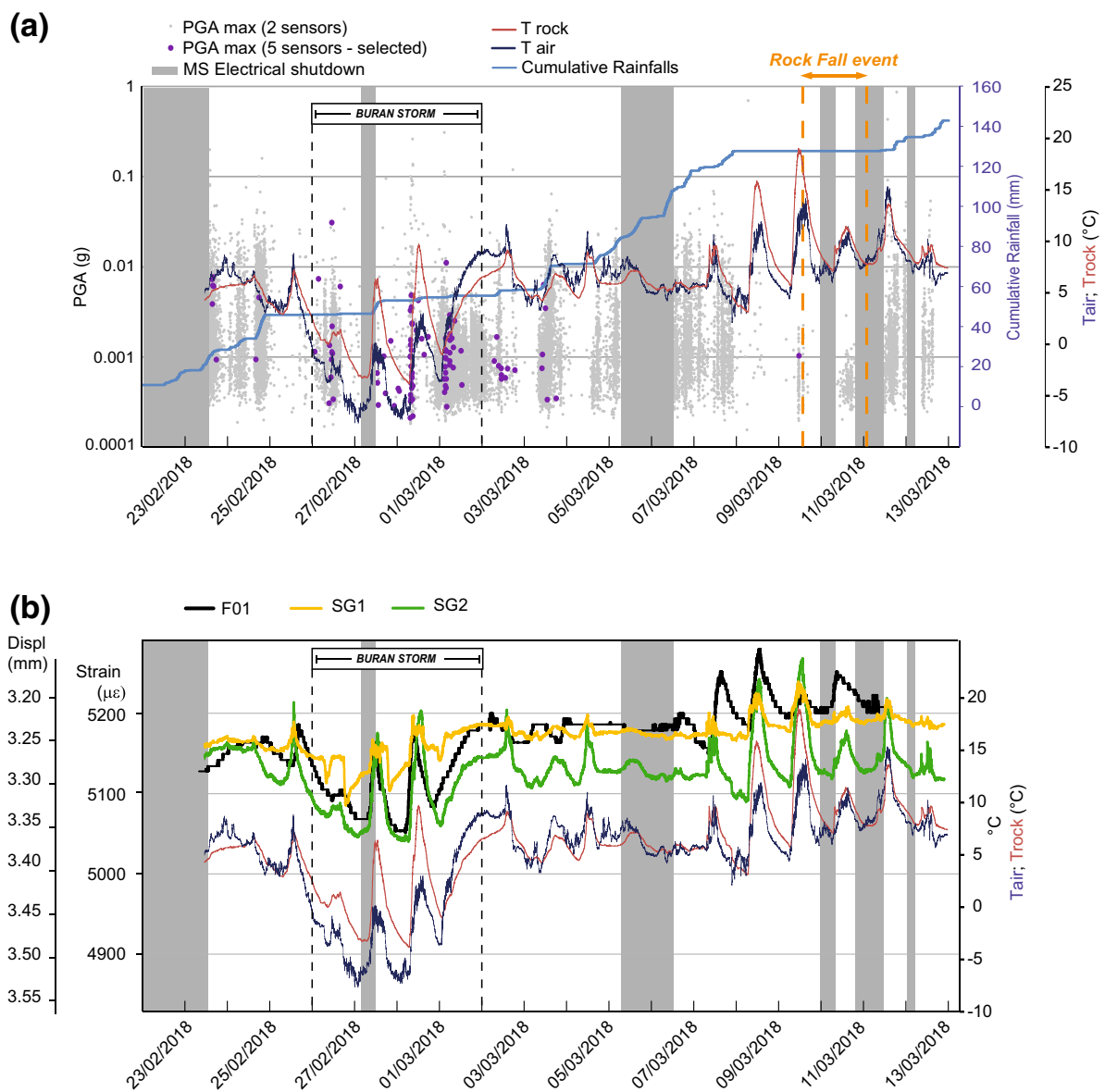

Fig. 5 a Distribution of the MS events recorded by two (grey dots) and five (purple dots) accelerometers respect to air and rock mass temperatures (dark blue and red lines, respectively) and cumulative rainfall (light blue line). The acquisition periods of the micro-seismic monitoring system and the Buran storm period are also shown. b elastic strain recorded for the strain gages (SG1 and SG2) and for the extensometer F01 
to guarantee a strongly restrictive approach, allowing the identification of $103 \mathrm{MS}$ events that had a high quality wave form and a consequently high certainty of the event type. These latter events were characterised by very short-time durations, i.e., in the order of hundredths of seconds and by a wide-varying frequency content ranging from 30 to $1200 \mathrm{~Hz}$. The selected MS events were categorised according to their time of occurrence: 44 occurred during dry periods (40 in the Buran storm and 2 in the pre/post-Buran storm) and 59 occurred during rainy periods (39 in the Buran storm and 20 in the pre/post-Buran storm) (Table 2). The maximum daily rate of MS events during the Buran period occurred on 28 February, during which there were 20 and 11 detections for rainy and dry periods, respectively, and during the pre/post-Buran storm, when seven and two events were detected on 2 March during the rainy and dry periods, respectively. This distribution is clearly visible in the synoptic graph shown in Fig. 5a, which shows the maximum PGA recorded from the six sensors for each MS event vs. the rainfall cumulative and the temperatures recorded in the air and the rock, where the MS events that had the highest PGA mainly occurred during the Buran storm period. This graph also reports the non-selected events, which were recorded simultaneously by 5 sensors and were, therefore, considered to be non-random seismic events. By focusing on the period characterised by the coldest temperature, which ranged from 27 February to 3 March, it was possible to distinguish three rising temperature trends: while no MS data were available during the first period, in concomitance with the second one and particularly with the last one, a marked increase in micro-seismicity was registered (Fig. 6). The spectrograms computed for the two exemplary MS events showed frequency contents of approximately 140 and $65 \mathrm{~Hz}$. Generally, the frequency maximum of the signals did not show peculiar features linked to the position of the sensor, resulting in random scattering among the accelerometers. In addition to the micro-seismic data, the extensometers and the strain gages only recorded the elastic deformation caused by variations in the rock temperature (i.e., heating dilation and cooling contraction), with a maximum daily amplitude of $165 \mu$ strain (Fig. 5b).

\section{Discussion}

The automated STA/LTA routine allowed an initial analysis of the distribution of detected events across the monitoring period: 18,802 events, registered to at least two sensors, were scattered throughout the entire period but contained many false positives, which were strongly reduced by considering the 1646 events simultaneously recorded by five accelerometers during the first ten days. This latter dataset was further minimised through manual selection of the waveforms to perform a more restrictive analysis and to remove doubtful MS events, resulting in the identification of 103 MS events that appeared clustered during the Buran storm period and immediately after it (Figs. 5 and 6). Therefore, the reliability of the micro-seismic monitoring system for the entire period was appraised; however, reliable MS events only clustered within a few days while steep thermal transient occurred.

The correlations among rainfall, rock temperature, and time distribution of MS events were investigated. With respect to rainfall, the daily cumulative data showed that the monitoring period was characterised by several rainy days, with a maximum of $23.2 \mathrm{~mm}$ on 6 March during the pre/post-Buran time window and $6.6 \mathrm{~mm}$ on 27 February during the Buran storm phase (Fig. 7c). Nonetheless, with respect to the $59 \mathrm{MS}$ events that occurred during rainy periods (2-h cumulative), 39 occurred during the Buran storm period and 20 in the pre/post-Buran storm phase ( 8 before 26 February and 12 after 2 March) but were 


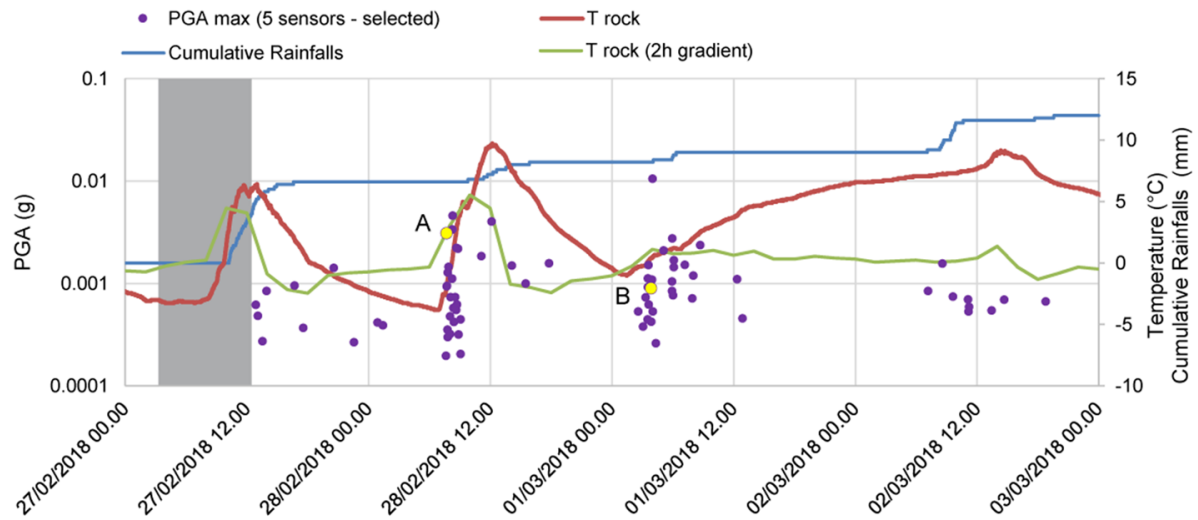

\section{Event A}

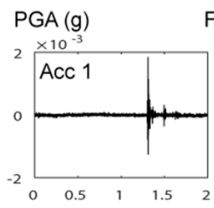

Frequency $(\mathrm{Hz})$

PSD $P G A(g)$

\section{Event B}

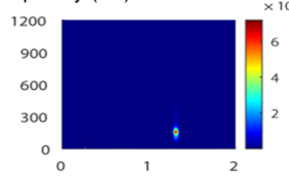

Frequency $(\mathrm{Hz})$

PSD
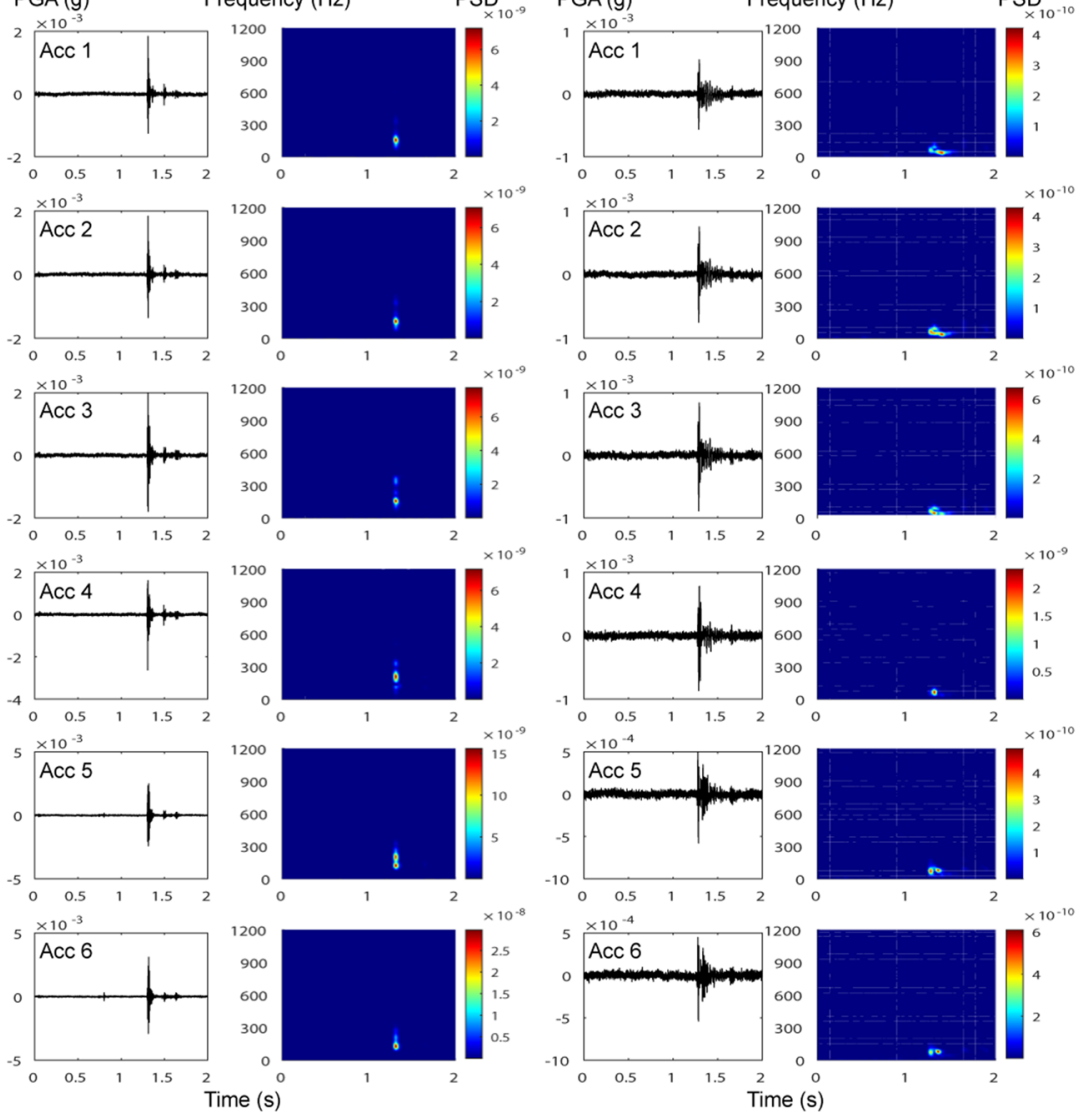

Fig. 6 Distribution of MS events during the Buran storm (see the time window reported in Fig. 5): a major cluster corresponds to the highest rock mass temperature rate and to the absolute minimum recorded in rock. The time history and the spectrogram from short-time Fourier transformations are also reported for events $\mathrm{A}$ and $\mathrm{B}$ identified in the upper panel 


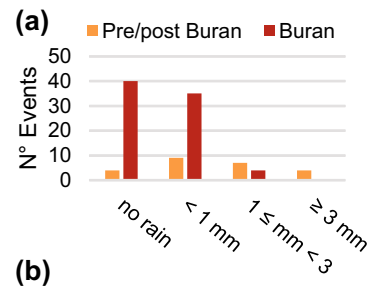

(c)
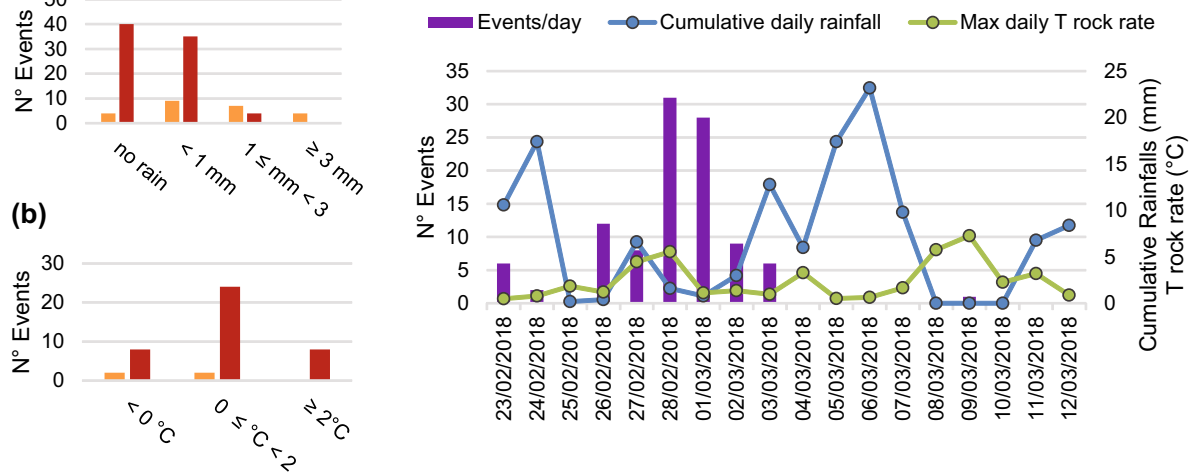

Fig. 7 MS events count in the pre/post-Buran and Buran storm period considering cumulative rainfalls (a) and rock temperature $2 \mathrm{~h}$ rate (b). In $\mathbf{c}$ the daily events, cumulative rainfall, and maximum rock temperature rate are reported

scarcely correlated with the rainiest days. No events were identified after 4 March, while 20 events occurred on 28 February, and only 6 occurred on the previous day, which was characterised by a larger amount of rainfall. A major cluster of events occurred in concomitance with a small amount of cumulated rain $(<1 \mathrm{~mm})$, particularly during the Buran storm phase, while few other events arose for larger accumulations (Fig. 7a). Therefore, a scarce correlation appears between rainfall and MS events across the period, as shown by the cross-correlation that reported unreliable values for the lag for both the entire period and the pre/post-Buran phase, while a lag of $20 \mathrm{~h}$ resulted for the Buran storm period. This lag appeared to be very extensive compared to the $3 \mathrm{~h}$ lag obtained by Helmstetter and Garambois (2010); thus, other forcings might have acted during this period.

It was determined that the rainy periods that occurred during the Buran storm should not be taken into account for two primary reasons: (1) this period was characterised by snowfall rather than rainfall, and (2) the pre/post-Buran period enables the consideration of rainfall in almost entirely stationary conditions of rock mass temperature. These hypotheses are confirmed by the maintenance of the micro-seismic array that was carried out on 27 February (Fig. 2) during which the quarry was covered by snow, and the rain gage consequently measured snow melt on the considered day. Based on this evidence, a correlation between rainfall and MS during the Buran phase likely does not exist, while the occurrence of the described sharp thermal transient played a key role in triggering the micro-seismicity that occurred during this time interval.

As a further test of the reliability of this hypothesis, among the MS events that occurred in the absence of rainfalls (i.e., dry periods), a high proportion was recorded during the Buran storm (40 MS events), while significantly fewer occurred during the pre/post-Buran storm periods (4 MS events). To correlate the occurrences of MS events to the rock mass temperature, excluding possible interferences due to rainfalls, micro-seismicity was analysed in connection to the thermal gradient derived in $2 \mathrm{~h}$ intervals within the dry periods both during and pre/post-Buran storm (Fig. 7b). This approach highlighted the fact that the MS events mainly occurred in response to positive thermal gradients, particularly focused at the end of the Buran storm, when the temperature rose above $0{ }^{\circ} \mathrm{C}$ (Fig. 6). By referring to the absolute rock temperature, the Buran storm was characterised by MS events that 
mainly occurred when the temperature was higher than $3{ }^{\circ} \mathrm{C}$ and ranged between -1 and $1{ }^{\circ} \mathrm{C}$, while only a few coherent events occurred in the pre/post-Buran storm. Moreover, by considering the recorded rock mass temperatures, it is worth noting the absence of a minimum peak in the time window ranging from 1 to 3 March 2018, implying a rising temperature trend for a longer period, during which most of the MS events occurred (Figs. 5 and 6). This evidence demonstrated that while the rock mass temperature always fluctuates according to air temperature with an associated variation of the elastic strain recorded by the extensometer and the strain gages, the MS data were focused only along the heating ramps after the Buran storm (Figs. 5 and 6). Given the sudden temperature decrease, it is possible to assume that the snowfalls were associated with the favoured cooling and subsequent freezing of the water-permeated joints, at least in the external thermal active layer (i.e., the first $8 \mathrm{~cm}$ from the surface; Fiorucci et al. 2018; Marmoni et al. 2020), as demonstrated by the negative temperature values recorded by the thermometer within the rock mass. However, no instrumental constraints on the wetness conditions of joints are available to date. These findings are in agreement with the maximum rate of daily events, which fell on 1-2 March, during which 18 MS events were detected throughout a dry period. Furthermore, based on the maximum daily value of the $2 \mathrm{~h}$ rate of rock temperature (Fig. $7 \mathrm{c}$ ), a marked temperature variation similar to that experienced during the Buran storm period occurred between 7 and 10 March. However, even short lacks in power supply did occur, only $1 \mathrm{MS}$ event characterised this period. This evidence is supported by the cross-correlation performed between MS data and the rock temperature gradient. While no correlation existed in the pre/post-Buran period, the highest similarity was found at zero lag during both the Buran phase and the entire period.

Based on the observations concerning the cluster of MS events after the thermal minimum phase, supported by screening the occurrences of the events with regard to the rock temperature rate, the following outputs were inferred: (1) the MS events were mainly related to the rock mass response to a transient thermal forcing that likely froze the rock mass with a consequent release of the accumulated inelastic strain; (2) a thermal threshold controlled the thermal stresses acting in the rock mass, as the micro-seismicity occurred only in concomitance with the lowest recorded temperatures (during the Buran storm) and no relevant MS events were detected in the following period. In fact, more intense MS events occurred after the sharp change in air and rock mass temperatures that fell below

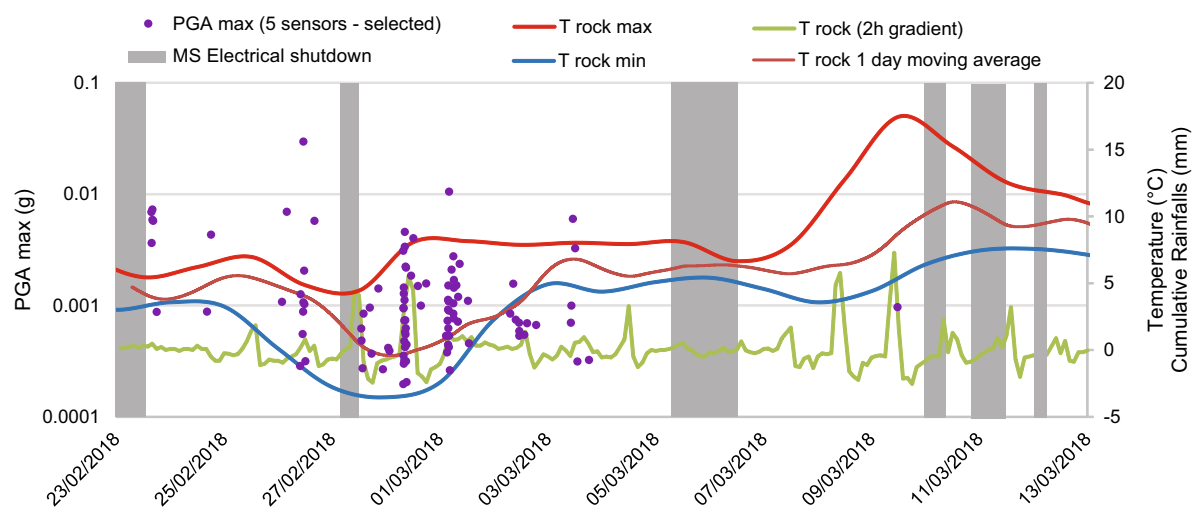

Fig. 8 MS events distribution, rock temperature $2 \mathrm{~h}$ rate and one-day moving average 
$0{ }^{\circ} \mathrm{C}$; on the contrary, no MS events were detected in the following days (8-10 March), when the temperature values increased to the seasonal average values. This trend is visible in Fig. 8, where the one-day moving average of the rock temperature, obtained to flatten the daily temperature oscillations to better observing its long-term variations, showed a concavity (i.e., colder temperature) during the Buran storm period, while this trend was not shown from 8 to 10 March.

Contrary to Amitrano et al. (2010) and Occhiena et al. (2012), the MS events were mainly distributed throughout the heating phase of the rock mass rather than during the cooling phase (Fig. 6), associating these events with the thermal expansion of the rock mass. Such differing results could be identified as the response of a complex system composed of intact rock and joints, where the strain accommodation does not necessarily reproduce the theoretical scheme of dilations and contractions assumed for an intact rock as well as a poorly jointed rock mass. Unfortunately, the micro-seismic dataset was not completed prior to the Buran storm occurrence, as the 6-accelerometers micro-seismic monitoring system was installed only a few days before the meteorological event; therefore, the reported considerations are mainly based on the MS data recorded after the Buran storm.

Contrary to Helmstetter and Garambois (2010) and Arosio et al. (2018), this study showed a scarce correlation between MS data and rainfalls, as reported by Colombero et al. (2018). The available recorded data allowed the observation of an intensification of the MS events due to the temperature drop experienced by the rock mass during the Buran storm. In agreement with Frayssines and Hantz (2006), ice jacking could be explored as the main factor responsible for MS events. Ice formation across the rock mass joints likely led to the accumulation of inelastic strain that was consequently released as micro-seismicity when the ice started melting.

Only elastic strains were recorded in the monitored joints, due to the punctual information provided by the installed sensors; however, the registered elastic cycles can be regarded as a reference for the strain suffered by the entire rock wall.

Even if the deployed accelerometers covered only a limited sector of the rock face, a similar vibrational behaviour may have affected other rock mass portions, such as that where the rock fall originated. This assumption can be supported by the close distance and common exposure to thermal forcing of the instrumented block and the rock fall sector (Fig. 3). It is worth noting that no rock falls occurred since the installation of the AiCP device, and no similar low absolute temperature or cooling/heating rates were recorded at the Field Laboratory; therefore, supplementary analyses were performed to study the possible relationship between the occurrence of small-size rock fall events and the thermal transience experienced at the Field Laboratory. The instability phenomenon was likely triggered by high-angle and conjugate joint sets (evident from the pre-failure model of this sector - Fig. 4a) partially back filled by the brownish soil also observed in the deposit (Fig. 4b). The comparison of the 3D models of the quarry sector, realised before and after the slope failure, enabled the determination of the source area, while the frames acquired by the AiCP device permitted the detection of accumulation and constrained its occurrence between 11 and 12 March, approximately 10 days after the end of the Buran storm.

Although no micro-seismicity was recorded before the collapse, this time lag seems to be compatible with a freeze-thaw driven failure, in agreement with similar cases reported in the literature. In fact, Levy et al. (2010) studied the pre-failure behaviour of the Chamousset rock column, which collapsed two weeks after a decrease in air temperature that favoured freeze-thaw cycles. Frayssines and Hantz (2006) suggested that for limestone cliffs, such as those present in the Chamousset and the Acuto sites, frost can penetrate faster and deeper into opened joints than in a more contiguous rock mass due 
to the efficient heat transfer associated with cold airflow in the opened joints. Moreover, the water seeping during the thaw phase may have contributed to decreasing the available rock mass strength in the sealed joints. Even if it is not possible to directly relate the rock fall to a specific triggering event, the above data demonstrate that rock mass damage occurs as a preparatory condition for rock failures and is related to the freeze-thaw effect linked to the short thermal transient associated with the Buran storm.

The here obtained findings highlights the relevance of preparatory conditions in the occurrence of rock failures, as a result of environmental forcings to highlight the jointed contribution of predisposing, preparatory, and triggering factors in causing rock failures and to individuate the precursory events of collapses relevant for developing a hazard mitigation strategy. The rock failure monitoring and event-to-trigger correlation primarily contribute to reducing vulnerability and the associated damage, with the potential to outline a structural resilience strategy.

\section{Conclusions}

This study presented and discussed the records of a multi-sensor monitoring system, installed at the Acuto quarry Field Laboratory (Central Italy), collected during the Buran storm, a transient weather event characterised by a sharp change in the seasonal temperature trend. According to rock temperature data, the Buran storm and the pre/ post-Buran storm periods were distinguished. A micro-seismic monitoring system was installed to detect the vibrational emissions from a rock block partially detached from the rock wall: MS events over and through the 18-days monitoring period were compared with thermal and rainfall data to infer the role of intense thermal and pluviometric transient forcings in the vibrational and deformational responses of the monitored rock block. Many low-intensity MS events were recorded, but only 103 MS events manually selected from those detected by at least 5 sensors were included in the analysis: 44 events occurred during dry periods and 59 events occurred during rainy periods. No significant correlation between the MS events and rainfall events was found, while a major cluster of events corresponded to the periods that were characterised by a thermal minimum. In fact, the MS events detected during the Buran storm were of one order of magnitude higher than these that occurred in the pre/post-Buran storm, with $18 \mathrm{MS}$ events occurring from 1 to 2 March during a rising temperature after rock joint freezing. These findings prove the key role of thermal factors in stressing the rock mass and confirm the importance of integrating seismic monitoring techniques with contact stress-strain techniques to study the deformative effects acting on rock block and rock mass scales by different environmental forcings.

Acknowledgements The Authors thanks P. Sarandrea and the Municipality of Acuto for supporting the experimental activities in the quarry. The data analysis is part of the Ph.D. research of D. D'Angiò, carried out at the Department of Earth Sciences of the University of Rome "Sapienza" in cooperation with the French institute IFSTTAR (Institut Francais des sciences et technologies des transports, de l'amenagement et des reseaux) of Paris. The authors wish to thank F. Fuchs and another anonymous reviewer for their comments which helped improve the quality of the manuscript. This research is framed by the Department of Earth Sciences of the University of Rome "Sapienza" in the MIUR "Departments of Excellence" project (2018-2022), which includes the Acuto quarry as a Field Laboratory (Scientific Responsible Prof. S. Martino, email: acutofieldlab.dst@uniroma1.it). 
Author contributions D.D., L.L. and M.F. processed and analysed the seismometric data. G.M.M. and M.F. processed the thermo-pluviometric and strain data. D.D., M.F., R.I., L.L., G.M. M., and S.M. discussed and provided interpretation of seismometric and environmental datasets. A.F. managed the AiCP and performed the photogrammetric survey. S.M. coordinated the research activity and planned the experimental phases. All the authors wrote the manuscript and edited figures and tables.

Funding Open Access funding provided by Università degli Studi di Roma La Sapienza.

Open Access This article is licensed under a Creative Commons Attribution 4.0 International License, which permits use, sharing, adaptation, distribution and reproduction in any medium or format, as long as you give appropriate credit to the original author(s) and the source, provide a link to the Creative Commons licence, and indicate if changes were made. The images or other third party material in this article are included in the article's Creative Commons licence, unless indicated otherwise in a credit line to the material. If material is not included in the article's Creative Commons licence and your intended use is not permitted by statutory regulation or exceeds the permitted use, you will need to obtain permission directly from the copyright holder. To view a copy of this licence, visit http://creativecommons.org/licenses/by/4.0/.

\section{References}

Allen R (1982) Automatic phase pickers: their present use and future prospects. Bull Seismol Soc Am $225-242$

Amitrano D, Arattano M, Chiarle M et al (2010) Microseismic activity analysis for the study of the rupture mechanisms in unstable rock masses. Nat Hazards Earth Syst Sci 10:831-841. https://doi.org/10.5194/ nhess-10-831-2010

Arosio D, Longoni L, Papini M et al (2018) Analysis of microseismic signals collected on an unstable rock face in the Italian Prealps. Geophys J Int 213:475-488. https://doi.org/10.1093/gji/ggy010

Blasi C (1994) Fitoclimatologia del Lazio. Fitosociologia 27:1-56

Bottelin P, Jongmans D, Baillet L et al (2013) Spectral analysis of prone-to-fall rock compartments using ambient vibrations. J Environ Eng Geophys 18:205-217. https://doi.org/10.2113/jeeg18.4.205

Brückl E, Parotidis M (2005) Prediction of slope instabilities due to deep-seated gravitational creep. Nat Hazards Earth Syst Sci 5:155-172. https://doi.org/10.5194/nhess-5-155-2005

Collins BD, Stock GM (2016) Rockfall triggering by cyclic thermal stressing of exfoliation fractures. Nat Geosci 9:395-400. https://doi.org/10.1038/ngeo2686

Collins BD, Stock GM, Eppes M et al (2014) Thermal influences on spontaneous rock dome exfoliation. Nat Commun. https://doi.org/10.1038/s41467-017-02728-1

Colombero C, Comina C, Umili G, Vinciguerra S (2016) Multiscale geophysical characterization of an unstable rock mass. Tectonophysics 675:275-289. https://doi.org/10.1016/j.tecto.2016.02.045

Colombero C, Comina C, Vinciguerra S, Benson PM (2018) Microseismicity of an unstable rock mass: from field monitoring to laboratory testing. J Geophys Res Solid Earth 123(2):1673-1693

D'Amato J, Hantz D, Guerin A et al (2016) Influence of meteorological factors on rockfall occurrence in a middle mountain limestone cliff. Nat Hazards Earth Syst Sci 16:719-735. https://doi.org/10.5194/ nhess-16-719-2016

Delonca A, Gunzburger Y, Verdel T (2014) Statistical correlation between meteorological and rockfall databases. Nat Hazards Earth Syst Sci 14:1953-1964. https://doi.org/10.5194/nhess-14-1953-2014

Dietze M, Mohadjer S, Turowski JM et al (2017) Seismic monitoring of small alpine rockfalls - validity, precision and limitations. Earth Surf Dyn 5:653-668

Fantini A, Magrini M, Martino S et al (2015) Experimenting an embedded-sensor network for early warning of natural risks due to fast failures along railways. In: Proceedings of the 5th international workshop on image mining. Theory and applications, Berlin, pp 85-91

Fantini A, Fiorucci M, Martino S (2017a) Rock falls impacting railway tracks: detection analysis through an artificial intelligence camera prototype. Wirel Commun Mob Comput 2017:1-11. https://doi. org/10.1155/2017/9386928

Fantini A, Fiorucci M, Martino S, Paciello A (2017b) Investigating rock mass failure precursors using a multi-sensor monitoring system: preliminary results from a test-site (Acuto, Italy). Procedia Eng 191:188-195. https://doi.org/10.1016/j.proeng.2017.05.171

Fiorucci M, Marmoni GM, Martino S, Mazzanti P (2018) Thermal response of jointed rock masses inferred from infrared thermographic surveying (Acuto test-site, Italy). Sensors (Switzerland). https://doi. org/10.3390/s18072221 
Fiorucci M, Martino S, Bozzano F, Prestininzi A (2020) Comparison of approaches for data analysis of multi-parametric monitoring systems: insights from the Acuto test-site (Central Italy). Appl Sci 10(21):7658

Fischer L, Purves RS, Huggel C et al (2012) On the influence of topographic, geological and cryospheric factors on rock avalanches and rockfalls in high-mountain areas. Nat Hazards Earth Syst Sci 12:241254. https://doi.org/10.5194/nhess-12-241-2012

Frayssines M, Hantz D (2006) Failure mechanisms and triggering factors in calcareous cliffs of the Subalpine Ranges (French Alps). Eng Geol 86:256-270. https://doi.org/10.1016/j.enggeo.2006.05.009

Gischig VS, Moore JR, Evans KF et al (2011) Thermomechanical forcing of deep rock slope deformation: 1. conceptual study of a simplified slope. J Geophys Res Earth Surf 116:1-18. https://doi. org/10.1029/2011JF002006

Goldstein, P., Dodge D, Firpo M, Minner L (2003) SAC2000: Signal processing and analysis tools for seismologists and engineers. In: WHK Lee, Kanamori H, Jennings PC, Kisslinger C (eds) The IASPEI International Handbook of Earthquake and Engineering Seismology, Academic Press, London

Goldstein P, Snoke A (2005) SAC Availability for the IRIS Community. Inc Institutions Seismol Data Manag Cent Electron Newsl

Got JL, Mourot P, Grangeon J (2010) Pre-failure behaviour of an unstable limestone cliff from displacement and seismic data. Nat Hazards Earth Syst Sci 10:819-829. https://doi.org/10.5194/nhess-10-819-2010

Grämiger LM, Moore JR, Gischig VS, Loew S (2018) Thermomechanical stresses drive damage of alpine valley rock walls during repeat glacial cycles. J Geophys Res Earth Surf 123:2620-2646. https://doi. org/10.1029/2018JF004626

Grøneng G, Lu M, Nilsen B, Jenssen AK (2010) Modelling of time-dependent behavior of the basal sliding surface of the Åknes rockslide area in western Norway. Eng Geol 114:414-422. https://doi. org/10.1016/j.enggeo.2010.05.017

Gunzburger Y, Merrien-Soukatchoff V, Guglielmi Y (2005) Influence of daily surface temperature fluctuations on rock slope stability: case study of the Rochers de Valabres slope (France). Int J Rock Mech Min Sci 42:331-349. https://doi.org/10.1016/j.ijrmms.2004.11.003

Helmstetter A, Garambois S (2010) Seismic monitoring of Schilienne rockslide (French Alps): analysis of seismic signals and their correlation with rainfalls. J Geophys Res Earth Surf 115:1-15. https://doi. org/10.1029/2009JF001532

Kleinbrod U, Burjánek J, Fäh D (2017) On the seismic response of instable rock slopes based on ambient vibration recordings. Earth Planets Sp. https://doi.org/10.1186/s40623-017-0712-5

Koukouvelas I, Litoseliti A, Nikolakopoulos K, Zygouri V (2015) Earthquake triggered rock falls and their role in the development of a rock slope: the case of Skolis Mountain, Greece. Eng Geol 191:71-85. https://doi.org/10.1016/j.enggeo.2015.03.011

Krautblatter M, Moser M (2009) A nonlinear model coupling rockfall and rainfall intensity based on a four year measurement in a high alpine rock wall (Reintal, German Alps ). Nat Hazards Earth Syst Sci 9:1425-1432

Lague D, Brodu N, Leroux J (2013) Accurate 3D comparison of complex topography with terrestrial laser scanner: application to the Rangitikei canyon (NZ). ISPRS J Photogramm 82:10-26. https://doi. org/10.1016/j.isprsjprs.2013.04.009

Leone GR, Magrini M, Moroni D et al (2016) A smart device for monitoring railway tracks in remote areas. In: Proceedings of the international workshop on computational intelligence for multimedia understanding. IWCIM 2016

Lévy C, Baillet L, Jongmans D et al (2010) Dynamic response of the Chamousset rock column (Western Alps, France). J Geophys Res Earth Surf 115:1-13. https://doi.org/10.1029/2009JF001606

Levy C, Jongmans D, Baillet L (2011) Analysis of seismic signals recorded on a prone-to-fall rock column (Vercors massif, French Alps). Geophys J Int 186:296-310. https://doi.org/10.1111/j.1365246X.2011.05046.x

Loew S, Gschwind S, Gischig V et al (2017) Monitoring and early warning of the 2012 Preonzo catastrophic rockslope failure. Landslides 14:141-154. https://doi.org/10.1007/s10346-016-0701-y

Mateos RM, García-Moreno I, Azañón JM (2012) Freeze-thaw cycles and rainfall as triggering factors of mass movements in a warm Mediterranean region: the case of the Tramuntana Range (Majorca, Spain). Landslides 9:417-432. https://doi.org/10.1007/s10346-011-0290-8

Matsuoka N (2019) A multi-method monitoring of timing, magnitude and origin of rockfall activity in the Japanese Alps. Geomorphology 336:65-76. https://doi.org/10.1016/j.geomorph.2019.03.023

Matsuoka N, Sakai H (1999) Rockfall activity from an alpine cliff during thawing periods. Geomorphology 28:309-328. https://doi.org/10.1016/S0169-555X(98)00116-0

Marmoni GM, Fiorucci M, Grechi G, Martino S (2020) Modelling of thermo-mechanical effects in a rock quarry wall induced by near-surface temperature fluctuations. Int J Rock Mech Min Sci 134:104440 
Menéndez Duarte R, Marquìnez J (2002) The influence of environmental and lithologic factors on rockfall at a regional scale: an evaluation using GIS. Geomorphology 43:117-136

Meyer M, Weber S, Beutel J, Thiele L (2019) Systematic identification of external influences in multi-year microseismic recordings using convolutional neural networks. Earth Surf Dyn 7:171-190

Moore JR, Gischig V, Burjanek J, et al (2012) Earthquake-triggered rock slope failures: Damage and site effects. In: Proceedings of the 11th International \& 2nd North American Symposium on Landslides. pp 1-11

Occhiena C, Coviello V, Arattano M et al (2012) Analysis of microseismic signals and temperature recordings for rock slope stability investigations in high mountain areas. Nat Hazards Earth Syst Sci 12:2283-2298. https://doi.org/10.5194/nhess-12-2283-2012

Papini M, Alba M, Longoni L et al (2009) Towards rockfall forecasting through observing deformations and listening to microseismic emissions. Nat Hazards Earth Syst Sci 9:1119-1131. https://doi.org/10.5194/ nhess-9-1119-2009

Provost F, Malet JP, Hibert C et al (2018) Towards a standard typology of endogenous landslide seismic sources. Earth Surf Dyn 6:1059-1088. https://doi.org/10.5194/esurf-6-1059-2018

Senfaute G, Duperret A, Lawrence JA (2009) Micro-seismic precursory cracks prior to rock-fall on coastal chalk cliffs: a case study at Mesnil-Val, Normandie, NW France. Nat Hazards Earth Syst Sci 9:16251641. https://doi.org/10.5194/nhess-9-1625-2009

Trnkoczy A (2012) Understanding and parameter setting of STA/LTA trigger algorithm. In: Bormann P (ed) New Manual of Seismological Observatory Practice 2 (NMSOP-2), Deutsches GeoForschungsZentrum GFZ, Potsdam, pp 1-20

Valentin J, Capron A, Jongmans D et al (2017) The dynamic response of prone-to-fall columns to ambient vibrations: comparison between measurements and numerical modelling. Geophys J Int 208:10581076. https://doi.org/10.1093/gji/ggw440

Varnes DJ (1978) Slope movement types and processes. In: Schuster RL, Krizek RJ (eds) Landslides Analysis and Control, Special Report 176. National Academy of Science, pp 11-33

Walbert C, Eslami J, Beaucour AL et al (2015) Evolution of the mechanical behaviour of limestone subjected to freeze-thaw cycles. Environ Earth Sci 74(7):6339-6351. https://doi.org/10.1007/s1266 5-015-4658-2

Wang P, Xu J, Liu S et al (2016) A prediction model for the dynamic mechanical degradation of sedimentary rock after a long-term freeze-thaw weathering: considering the strain-rate effect. Cold Reg Sci Technol 131:16-23. https://doi.org/10.1016/j.coldregions.2016.08.003

Weber S, Faillettaz J, Meyer M et al (2018) Acoustic and microseismic characterization in steep bedrock permafrost on Matterhorn (CH). J Geophys Res Earth Surf 123:1363-1385. https://doi.org/10.1029/2018J F004615

Xu N, Tang C, Li H et al (2012) Excavation-induced microseismicity: microseismic monitoring and numerical simulation. J Zhejiang Univ Sci A 13:445-460. https://doi.org/10.1631/jzus.a1100131

Xu NW, Dai F, Liang ZZ et al (2014a) The dynamic evaluation of rock slope stability considering the effects of microseismic damage. Rock Mech Rock Eng 47:621-642. https://doi.org/10.1007/s0060 3-013-0432-5

Xu T, Xu Q, Deng M et al (2014b) A numerical analysis of rock creep-induced slide: a case study from Jiweishan Mountain, China. Environ Earth Sci 72:2111-2128. https://doi.org/10.1007/s1266 5-014-3119-7

Zhou J, Wei J, Yang T et al (2018) Damage analysis of rock mass coupling joints, water and microseismicity. Tunn Undergr Sp Technol 71:366-381. https://doi.org/10.1016/j.tust.2017.09.006

Publisher's Note Springer Nature remains neutral with regard to jurisdictional claims in published maps and institutional affiliations. 